\title{
L2 Pragmatic Competence in Chinese Secondary Schools - Teaching Approaches, Teaching Materials, and Classroom-Based Assessment
}

\author{
Qing Liu ${ }^{1}$ \\ ${ }^{1}$ Independent, Handan, China \\ Correspondence: Qing Liu, Independent, Handan, China.
}

Received: June 4, 2019

Accepted: June 28, 2019

Online Published: June 28, 2019

doi:10.20849/aes.v4i1.604

URL: https://doi.org/10.20849/aes.v4i1.604

\begin{abstract}
English as a L2 (second language) is compulsory in many countries' education. However, the pragmatic competence is far less developed, compared with the grammatical competence. This situation leads to a fact that many students are confident in grammar-oriented tests, but afraid of starting a conversation. Or, in many cases, the students may bewilder the native speakers. This paper concerns the teachability of L2 (Second Language) pragmatic competence in Chinese secondary schools. It starts with a relatively comprehensive introduction of some very basic concepts, including pragmatics, pragmatic competence, and ILP (interlanguage pragmatics). Next, the necessity of consciously learning of L2 pragmatic competence is discussed within the specific context, as well as its teachability. After that, challenges of L2 pragmatic competence teaching are raised from three aspects: 1) challenges for teachers in the teaching process; 2) lack of authentic L2 pragmatic input; and 3) the testing and assessment of L2 pragmatic competence. Finally, feasible ways to facilitate the teaching application of L2 pragmatic competence are proposed.
\end{abstract}

Keywords: L2 pragmatic competence, secondary schools, pragmatic teaching, authentic materials, classroom-based assessment

\section{Introduction}

In China, English learning is compulsory from primary schools to universities. The grades of English exams are always seriously taken from entrance exams to College English Tests. However, the ultimate goal of learning English as Foreign Language (EFL) is not taking tests, but communicating. Therefore, EFL learners should arm themselves with communicative competence which is composed of four components: sociolinguistic competence, discourse competence, strategic competence and grammatical competence. Pragmatic competence has overlaps with some of them. Therefore, Alcón-Soler and Martinez-Flor (2008: 5) states that "communicative competence is not only achieved by improving learners' grammatical knowledge, but it also concerns the development of discourse and pragmatic competences, among others". Roever (2009: 561) also highlights that "communicative competence should translate into pragmatics receiving pedagogical attention equal to grammar or vocabulary". However, the pragmatic competence is far less developed than the grammatical competence (Eslami \& Eslami-Rasekh, 2008). Besides, the attention of teaching and learning pragmatic competence need to be raised. Thus, this assignment aims to provide facilitators in the teaching of pragmatics.

The assignment will begin with an introduction of a few very basic concepts about pragmatics as background knowledge, followed by an analysis the requirement of L2 pragmatic learning and teaching by investigating the acquisition and teachability of L2 pragmatic competence. In the next part, prominent challenges in Chinese secondary schools' pragmatic teaching will be presented, and corresponding suggestions will be addressed. A brief conclusion will be drawn in the end.

\section{Background Knowledge About Pragmatics}

The definition and research focus of pragmatics will be discussed. Then, pragmatic competence as a component of language competence and its sub-abilities will be presented. Interlanguage pragmatics (ILP) and pragmatic competence in second language (L2) context will be briefly introduced in the end.

\subsection{What Is Pragmatics?}

Pragmatics is a sub-discipline of linguistics. According to O'Keeffe, Clancy, and Adolphs (2011: 1), the development of modern usage of pragmatics begins with Morris's (1938) distinction of "syntax, semantics and 
pragmatics". Syntax is the study of linguistic forms and the sequence of words in sentences; semantics is the study of meaning of the linguistic forms and sequenced words; and "pragmatics is commonly viewed as the study of language in use" (Roever, 2009: 560). Various definitions and theories of pragmatics were proposed, but none is complete or generally agreed (Roever, 2013). The two proposals mentioned below is what I think is representative, among others. Based on the well-accepted idea of "relation of signs to their interpreters" (Morris, 1938: 30), Spencer-Oatey and Zegarac (2010: 70) propose that "pragmatics is concerned not with language as a system or product per se, but rather the interrelationship between language form, (communicated) messages and language users". In Longman Dictionary of Language Teaching and Applied Linguistics, pragmatics is defined as "the study of the use of language in communication, particularly the relationships between sentences and the contexts and situations in which they are used" (Richards \& Schmidt, 2013: 449).

The first description of pragmatics specifically points out the vital role of interlocutors (similar definition is also provided by Yule (1996)); the second one stresses the significance of contexts (researchers like Fasfold (1990), Levinson (1983) and Mey (2011) also emphasize context). It is very hard to explain the notion with a few sentences, because what pragmatics explores is more complex than syntax and semantics. From different definitions of pragmatics, four "core" phrases can be extracted: the utterance itself (both form and meaning), the addressors' intention, the addressees' interpretation, and the contextual factors (e.g. the situation in which the sentences are uttered, the relationship between the interlocutors, their social status, background knowledge, etc.); and pragmatics studies the relation among them.

\subsection{What Is Pragmatic Competence?}

A wide range of models were proposed to frame the competence of pragmatics. Building on previous theories and empirical evidence, an American applied linguist, Bachman (1990), proposed a relatively systematic taxonomy of language competence, in which pragmatic competence was first explicitly mentioned as an important construct of language competence (see Figure 1). It consists of illocutionary competence and sociolinguistic competence. The illocutionary competence here refers to the knowledge of the relation between language signs (or linguistic signals) and their functions (i.e. ideational, manipulative, heuristic, and imaginative); Sociolinguistic competence refers to the sensitivity to the appropriateness between the functions and the contexts of language (i.e. the sensitivity to dialects, registers and naturalness, and the ability to interpret cultural references and figures of speech) (ibid).

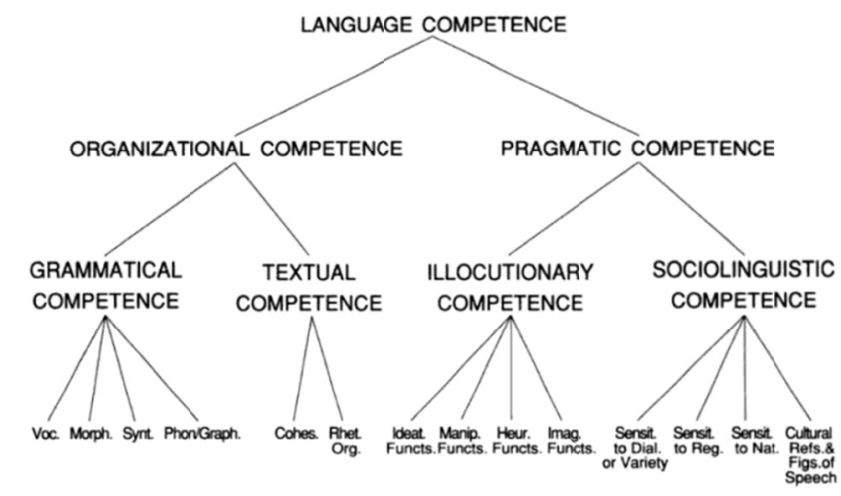

Figure 1. The schematic presentation of language competence (ibid: 87)

While Bachman's (1990) model begins from theories, recent interpretations of pragmatic competence usually stand from the language users' perspective and come into detailed abilities that they need to possess. Pragmatic competence refers to not only knowing and understanding pragmatic knowledge, but the ability of effectively using the knowledge as well (Cohen, 2010). In another way, we can say that having pragmatic competence is the command of pragmatic knowledge as both language receivers and producers. Bialystok (1993) believes that pragmatic competence embodies various subdivided abilities, among which the most significant three are: (1) (as speakers) the ability to use appropriate forms of language for different purposes according to the specific contexts; (2) (as listeners) the ability to understand the speakers' direct and indirect meaning; (3) (as both parts of a conversation) the ability to make a dialogue continue by pragmatic rules (e.g. cooperation, turn-taking). Cohen (2010) broadens our understanding of pragmatic competence by highlighting the easily neglected 
pragmatic knowledge in written language (e.g. e-mails), and particularly points out the ability of identifying and considering rhetorical structure in reading and writing. He also adds the ability of using and interpreting non-verbal cues (e.g. gestures, silence) as speakers and listeners.

\subsection{ILP and L2 Pragmatic Competence}

Similar to the general pragmatic research, L2 pragmatics (or ILP) also studies "speech acts, conversational structure, and conversational implicature"; but with a stronger focus on two aspects: knowledge relate to cross-cultural pragmatics, and issues relate to the development of L2 pragmatic competence (Alcón-Soler \& Martinez-Flor, 2008: 3). In addition, L2 pragmatic competence that we talked about can be distinguished between two ends: the linguistic end concerns the knowledge of language forms and linguistic devices (or means, or strategies) to perform communicative acts (i.e. communicative actions performed in spoken and written forms; even silence and nonverbal performance are included) and convey interpersonal meanings; and the social end concerns the knowledge of which means are appropriate in particular social and cultural contexts (ibid). The most frequently used terminology of the two ends of L2 pragmatics is first proposed by Leech (1983) and Thomas (1983) as pragmalinguistic and sociopragmatic. The two constructs model is well-accepted by linguists. For example, in Kasper and Roever's (2005: 318) opinion, one can only be considered as a pragmatically competent L2 learner when he/she have knowledge of both pragmalinguistic competence and sociopragmatic competence, and the ability "to understand and produce sociopragmatic meanings with pragmalinguistic conventions".

\section{The Requirement for Learning and Teaching L2 Pragmatic Competence}

Now, we know what L2 pragmatic competence is, does the acquisition request extra attention? Can the improvement be accelerated through teaching? Answers to the two questions are what will be sought in this section.

\subsection{Does L2 Pragmatic Knowledge Need to Be Learnt in Particular?}

By analysing empirical studies, Kasper (1997: 3) points out that there is some pragmatic knowledge that ESL/EFL learners can acquire on their own without extra learning in SLA: (1) Some general pragmatic knowledge is applicable in different languages. For example, there are basic organizational principles of conversations; utterances may have implied meanings; different strategies can be applied to soften or intensity communicative acts. Once the learners possess enough linguistic knowledge, they can create effective communicative acts in L2. (2) Some specific pragmatic knowledge in L1 can be directly applied in L2 communication "if there is a corresponding form-function mapping between L1 and L2" (e.g. using the past form of can/will to be formal and more polite in the speech act of request). Such knowledge in English is only shared by very limited Germanic languages like Danish, Dutch and German. In many other languages, take Chinese for example, the verbs do not have past forms at all.

However, only knowing some universal pragmatic knowledge does not mean that the ESL/EFL learners can effectively use it. Great differences exist between the production in mother tongue and in L2 when performing the same communicative acts. For example, comparing with L1 performance, less politeness markers are used and less sensitivity to the contextual factors is shown when one uses L2 (Kasper, 1981; Fukushima, 1990). Besides, what mentioned above is the acquisition of pragmatic knowledge among adult L2 learners. For younger learners like primary and secondary school students, whose L1 pragmatic knowledge is not fully developed, the need for particular learning of L2 pragmatics is much stronger. Furthermore, the universal and the can-be-transferred pragmatic knowledge is only a minor part, and obviously is not enough for successful communication. There is evidence that native speakers (NSs) and non-native speakers (NNSs) may have different interpretation on the same utterance (Bouton, 1988); the choice, content, and form of speech acts also appear to be differ between NSs and NNSs (Bardovi-Harlig, 2010). From the above, in order to improve pragmatic competence, to use the target language (TL) in a more similar way as the NSs do, and to communicate with less misunderstandings, L2 pragmatic knowledge need to be learnt in particular.

\subsection{The Teachability of L2 Pragmatic Competence}

Different from syntax and semantics which can be taught through grammar and vocabulary on the sentence and word level, pragmatics concerns not only the language itself but many other referents (e.g. listener, speaker, culture, etc.). Therefore, whether ILP can be taught was questioned and widely researched from early 1990s. The teachability research was greatly inspired by Kasper's (1997) report which then published as "Can Pragmatic Competence Be Taught?". The rich body of research falls into two approaches (i.e. a cognitive theoretical 
approach, or a socially oriented approach), which are in accordance with the second language acquisition (SLA) theories suggested by cognitivists and socioculturalists (Alcón-Soler \& Martinez-Flor, 2008).

The research conducted according to the former approach mainly follow Schmidt's $(1995,2001)$ noticing hypothesis and the Long's (1996) interactive hypothesis. From the findings of studies on a wide range of topics (e.g. discourse markers, strategies, pragmatic routines, pragmatic fluency, and the performance of a series of speech acts in context), a few most influential pattern about the teachability of L2 pragmatic competence and the efficacy of instructions can be concluded as following (mentioned in a review works, like Kasper, 1997; Rose, 2005; Alcón-Soler \& Martinez-Flor, 2008; Taguchi, 2015): (1) L2 pragmatic competence is teachable for all L2 learners, even for the novices. (2) Instructions (both explicit and deductive, and implicit and inductive) on a wide range of speech acts and pragmatic features are necessary and benefit the development of pragmatic competence impressively; (3) explicit and deductive instructions (with explicit explanation of metapragmatic information) are more helpful than the implicit and inductive ones; (4) high levels of attention-drawing activities are more effective than merely exposure to positive evidence.

Comparing with the cognitive approach, which treats the acquisition of pragmatics as an individual process, the studies set within the latter approach consider social interaction plays the most significant role. The sociocultural theory and the language socialization theory are the leading theories, following which the research concentrate on discovering the development issues through studying the characteristics of language which used by L2 learners at different stages of learning process. The findings of these research proved that L2 pragmatic competence is teachable in L2 classroom by offering opportunities for interaction in the TL (Hall, 1998), assistance from teachers or peers in the zone of proximal development (Ohta, 2001), knowledge about cultural values, and conventions of the TL community in the process of language teaching (Duff, 1995; Kanagy, 1999), etcetera.

In conclusion, although pragmatic competence, like any other competence, is a kind of special knowledge which can only be gained by the learners themselves and not teachable (Kasper, 1997). Teachers in L2 classrooms can assist the learners with their development and improvement of pragmatic competence by offering proper opportunities. Synthesizing the finding from the two approaches above, the opportunities here can be appropriate instructions, suitable activities, proper arrangement of pragmatic knowledge, and so on.

\section{L2 Pragmatics Teaching in Chinese Secondary Schools}

Since we know that L2 pragmatic competence is required and also teachable in L2/FL classrooms, here come our aims of this assignment: providing applicable facilitators to L2 pragmatics teaching. Before the recommendation of applicable approaches, the main factors which may impede pragmatic teaching in this particular teaching context will be presented. Thus, the "solutions" that we will propose can be more suitable to the target problems.

\subsection{The Challenges in Chinese Secondary Schools}

\subsubsection{Challenges for Teachers in the Teaching Process}

To facilitate students' development of L2 pragmatic competence, the teachers themselves should have well-developed pragmatic competence and the knowledge of how to teach pragmatics in the language classroom, and the individual differences of learners should also be taken in to consideration.

It is very difficult for teachers of Chinese secondary schools to play the role of facilitators in the development pragmatic competence due to the following reasons. Firstly, almost all English teachers are NNSs, and when they were learners, attention had not been paid on developing pragmatic competence and only very limited pragmatic knowledge was taught. So, the teachers' pragmatic competence is inadequate. Secondly, the teachers cannot receive sufficient knowledge on teaching pragmatics in the pre- and in-service training courses, because such courses mostly focus on improving the grade of exams. Thirdly, the traditional teaching approaches (e.g. grammar-translation) that teachers are familiar with usually target at imparting knowledge in the domain of syntax and semantics. A few approaches aim at cultivating communicative competence (e.g. communicative language teaching) were advocated and became prevalence, but the application is superficial (mainly applied in model classes for presentation and discussion, seldom being used in actual teaching). Even following the communicatively oriented approaches, pragmatic knowledge may only be mentioned parenthetically, and there is no systematically designed pragmatic-focused syllabus (Roever, 2009: 568). Fourthly, the class size of secondary schools is large (e.g. around 55 students in each class in my city), and the students are of mixed language levels (the situation exist in both junior and senior high schools). This means that the readiness of certain pragmatic knowledge varies in one class. 


\subsubsection{Lack of L2 Pragmatic Input}

The major difference between ESL context and EFL context is the extent of exposure to English. While purely exposure without instructions to TL is inadequate for the development of ILP (Rose, 2005), less exposure to TL can cause less access to authentic pragmatic input.

Though abundant resources in English can be found on the internet, the content is unfiltered, not all worth educational value, therefore is not suitable for most L2 learners. Besides, many learners do not have the motivation to learn L2 after the compulsory classes. Hence, interactions in the class and textbooks are still the main sources of pragmatic input. However, both sources have deficiencies. Except for those who live in international metropolis, most EFL learners only communicate in English with their teachers and peers in the class. The communication in classrooms is institutional, unsymmetrical, and has distinctive characteristics. For example, the speech acts in classroom interactions are rather limited, less politeness marker is used, the structure of discourse is monopoly, etc. (Kasper, 1997). While in the real-life communication, all kinds of pragmatic behaviour are valuable and need to be acquired in the learning process.

The major source of L2 pragmatic input, textbook, also has its deficiencies. Studies on teaching materials in many EFL countries show that the content of may textbooks cannot provide sufficient pragmatic knowledge (e.g. Crandall \& Basturkmen, 2004; Vellenga, 2004), and lack authenticity and reliability (e.g. Gilmore, 2004; Uso-Juan, 2007). Such shortages in supporting pragmatic development may be caused by its commercially marketed nature, and the content is not composed based on natural communications, but created by the writers with their unreliable intuitions (Cohen \& Ishihara, 2013). Comparing to textbooks in early years, some recent ones are optimized, but still have their own problems. For example, Nguyen's (2011) study on Vietnam's senior high schools' textbooks reports that speech acts in that series of textbooks is randomly distributed (whether recur or not); contextual and meta-pragmatic information (i.e. the appropriateness of language in terms of interlocutors' relationship, situation, context, etc.), which is critical to the pragmatic learning, is provided very few times. Li (2011: 138) also points out that speech acts in Chinese junior high schools' English textbooks lack of "directions of situations that the formulas are used". Consequently, the students' may speak only according to their preference and neglect (or do not know how to respond to) the contextual and meta-pragmatic information.

\subsubsection{Testing and Assessment of L2 Pragmatic Competence}

The testing of pragmatics is widely researched on both components of pragmatic competence (i.e. pragmalinguistic competence and sociopragmatic competence), and various batteries with reliability were proposed. However, the current exams for secondary school examinees are paper-based only, which decides that the testing of pragmatics can only cover a narrow range of receptive abilities (e.g. interpretation, perception, appropriateness and correct referents) through limited methods (rating, multiple choice, judgements, etc.). A great proportion of pragmatic competence (e.g. whether the students have the ability to produce appropriate, acceptable discourse with others) cannot be examined at all.

Another drawback is that the testing system has a negative effect on the pragmatic teaching. The current high-steak entrance exams still emphasis grammar and lack of a focus on pragmatics. Since the schools, parents, teachers and students all aim at higher marks for better high schools and universities, the formative assessment and the monthly exam are also designed in accordance with the entrance exams. In this case, the object of teaching and the class design will be greatly affected, even though the teachers begin to notice the importance of ILP and master the teaching techniques.

Some challenges mentioned above is decided by the practical condition (e.g. large class size, grammar-oriented and paper-and-pencil tests) and cannot be changed in a long time. Therefore, the suggestions to enhance the efficacy to the teaching and learning will only address what is applicable in actual teaching.

\subsection{Approaches, Materials, and Assessment}

\subsubsection{Approaches to Pragmatic Teaching}

In section 3.2, we mentioned that a series of studies prove that the groups with instructions outperformed than the ones without instructions, in turn, the result proves the effectiveness of the techniques applied in the studies. However, such instructions "are not embedded in a larger curricular sequence, ... the teaching of pragmatics has yet to be integrated well in curricula and go beyond occasional projects on isolated features" Roever (2009: 569).

With a careful review of previous research, Taguchi (2015: 29) proposed two sets of instructions to pragmatic teaching: "(1) explicit teaching with metapragmatic information and opportunities to produce target pragmatic forms; (2) implicit teaching involving structured practice for processing pragmatic rules." The first one follows an awareness-raising approach. The instruction mainly comes from Tateyama's $(2007,2009)$ research and 
considered to be "powerful enough to boost learning of the target forms" (Taguchi, 2015: 26). The first step is to provide explicit explanations about target pragmatic features and strategies, which is an extra help for "noticing" (the basic level of awareness and inevitable in SLA); the second step (productive practice of target forms) is a process of enhancement from the basic level to "understanding" (the higher level of awareness). The latter one is analyzed from a series of research conducted by Takimoto $(2006,2007,2009)$, and in line with an input processing theory and an inductive approach, which "aims to describe cognitive mechanisms that operate when the learner is processing input" (Taguchi, 2011: 292). The first step is offering sufficient input contains target features, which expects students to process and "understand" the provided knowledge; it is vital to have enough structured practices after the implicit instruction, because the internalization of pragmatic knowledge in this approach has three levels: "attention to form fist, followed by noticing the forms in context, and finally processing them to induce rules from input" (Taguchi, 2015: 28).

Which approach to choose need to take the students' characteristics into consideration? For example, the students may need less or much longer time to process the knowledge and induce the rules, therefore the inductive approach is not suitable in our teaching context. In mix-ability classes, the awareness-raising approach may be more effective, because it may be difficult for some students to "notice" the instructed knowledge. With the explicit and deductive instruction, the learning process becomes easier, for students are made to "notice" the pragmatic knowledge (Taguchi, 2015). If time permits, the productive practice of the second step should better be tasks-based activity, which is most similar to real life conversations (Barvodi-Harlig, 2013) and integrates pragmatics better than other forms of activities (Roever, 2009). The tasks should ensure the development of receptive and productive abilities, and pragmalinguistic and sociopragmatic competence (Ishihara, 2010).

\subsubsection{The Selection of Authentic Materials}

A careful compilation and selection of teaching materials is essential to enhance the value of input, especially for the textbook writers and teachers who work in EFL context "given that their learners have relatively limited access to authentic input and rely almost only on textbooks for language learning" (Nguyen, 2011: 26). Teaching material, which contains key factors of communicative acts, is an important input resource and may affect the design of activities and tasks (Taguchi, 2011). Besides, a reasonable match of teaching approaches and materials can maximize the outcomes of teaching. For example, ample authentic materials have same pragmatic features are required for inductive teaching. The textbook is neither enough nor authentic. Thus, teachers need to seek for other sources, like corpuses, video clips from films and dramas, online materials in different forms. Remember to cheque the resource for authenticity, and make sure the content is representative and effective.

\subsubsection{Classroom-Based Assessment as a Part of Teaching}

With appropriate pragmatic-focused teaching and materials, the students are expected to possess the instructed pragmatic knowledge. But how much have they learnt and how well they can produce need to be measured, and the classroom-based assessment of pragmatic competence is a wise choice. Ishihara (2010) even claims that teaching without assessment is not complete. The assessment can have one or more of the three focus: pragamalinguistic ability, sociopragmatic ability, and analytic ability (Ishihara, 2010). The instrument can be role-play, oral/written DCT, multiple choice questions, etc. In terms of the way of scoring, a "rubric" which has scales on performances is introduced. "The use of rubrics highlights important pragmatic aspects being focused on, and enables students and teachers alike to pay attention to those crucial aspects during instruction and assessment" (ibid: 292). Classroom-based assessment of pragmatic competence can benefit both students and teachers (Cohen, 2004: 5-6): (1) it provides opportunities for students to notice the importance of pragmatic knowledge and the benefits of mastering it; (2) the assessment can be a strong motivation of learning pragmatic knowledge; (3) it provides possibility for teachers to see "the relative control their students have in what may at times be a significant area for L2 performance"; (4) the result of assessment can inform the teachers whether the students have mastered the instructed content. Hence, the attention of applying in-classroom pragmatic assessment should be raised.

\section{Conclusion}

Although the grammar-oriented educational system causes a discrepancy between the development of pragmatic competence and grammatical competence, a growing attention on the learning and teaching of pragmatics has been raised from the relation between pragmatic competence and the constructs of communicative competence. As to the development of L2 pragmatic competence, learning and teaching with a pragmatic-focus is required. In terms of the challenges in pragmatic teaching, the prominent ones were categorized into teacher-, input-, and test-related issues. Two sets of instructions on pragmatic teaching were proposed and compared, between which the one in line with awareness-raising approach is considered to be more suitable for the target context. Since a 
close relationship exists between teaching, material, and classroom-based assessment, a brief description of material selection and the importance of classroom-based assessment is mentioned in the end.

\section{References}

Alcón-Soler, E., \& Martínez-Flor, A. (2008). Pragmatics in foreign language contexts. Investigating Pragmatics in Foreign Language Learning, Teaching and Testing, 30, 1.

Bachman, L. F. (1990). Fundamental considerations in language testing. Oxford University Press.

Bardovi-Harlig, K. (2010). Exploring the pragmatics of interlanguage pragmatics: Definition by design. Pragmatics Across Languages and Cultures, 7, 219-259.

Bardovi-Harlig, K. (2013). Developing L2 pragmatics. Language Learning, 63(s1), 68-86.

Bialystok, E. (1993). Symbolic representation and attentional control in pragmatic competence. Interlanguage Pragmatics, 3(1), 43-57.

Cohen, A. D. (2010). Coming to terms with pragmatics. Teaching and Learning Pragmatics (pp. 3-21).

Cohen, A. D. (2014). Towards increased classroom assessment of pragmatic ability. Iranian Journal of Language Testing, 4(1), 4-25.

Cohen, D., \& Ishihara, N. (2013). Pragmatics (pp. 113-126). Applied linguistics and materials development. A\&C Black.

Ishihara, N. (2010). Assessment of Pragmatics in the classroom. Teaching and Learning Pragmatics: Where Language and Culture Meet (pp. 286-317).

Ishihara, N. (2010). Theories of language acquisition and the teaching of pragmatics. Teaching and learning pragmatics: Where language and culture meet (pp. 99-122).

Kasper, G. (1997). Can pragmatic competence be taught? (NetWork \#6). HTML document. Honolulu: University of Hawai'i, Second Language Teaching \& Curriculum Center.

Kasper, G., \& Roever, C. (2005). Pragmatics in second language learning. Handbook of Research in Second Language Teaching and Learning, 1, 317-334.

Li, X. (2011). Can Pragmatic Competence Be Taught in an EFL Classroom?. Overseas English, 14, 071.

Nguyen, M. T. T. (2011). Learning to communicate in a globalized world: To what extent do school textbooks facilitate the development of intercultural pragmatic competence?. RELC Journal, 42(1), 17-30.

O'Keeffe, A., Clancy, B., \& Adolphs, S. (2011). Introducing pragmatics in use. Taylor \& Francis.

Richards, J. C., \& Schmidt, R. W. (2013). Longman dictionary of language teaching and applied linguistics. Routledge.

Roever, C. (2009). Teaching and Testing Pragmatics. The Handbook of Language Teaching (pp. 560-577).

Rose, K. R. (2005). On the effects of instruction in second language pragmatics. System, 33(3), 385-399.

Schmidt, R. W. (Ed.). (1995). Attention and awareness in foreign language learning (Vol. 9). Natl Foreign Lg Resource Ctr.

Spencer-Oatey, H., \& Zegerac, V. (2010). Pragmatics' in Schmitt, N. An Introduction to Applied Linguistics.

Taguchi, N. (2011). Teaching pragmatics: Trends and issues. Annual Review of Applied Linguistics, 31, 289-310.

Taguchi, N. (2015). Instructed pragmatics at a glance: Where instructional studies were, are, and should be going. Language Teaching, 48(01), 1-50.

\section{Copyrights}

Copyright for this article is retained by the author(s), with first publication rights granted to the journal.

This is an open-access article distributed under the terms and conditions of the Creative Commons Attribution license (http://creativecommons.org/licenses/by/4.0/). 